\title{
EL CONCEPTO DE FORMACIÓN Y LA SIGNIFICACIÓN DE LA TRADICIÓN HUMANIISTICA PARA LAS CIENCIAS DEL ESPÍRITU Y EL ARTE
}

\author{
THE CONCEPT OF ACADEMIC TRAINING AND THE MEANING OF
} HUMANISTIC TRADITION TO THE SCIENCES OF ART AND SPIRIT

O CONCEITO DE FORMAÇÃO E O SENTIDO DA TRADIÇÃO HUMANÍSTICA PARA AS ÇIÊNCIAS DO ESPIIRITO E A ARTE

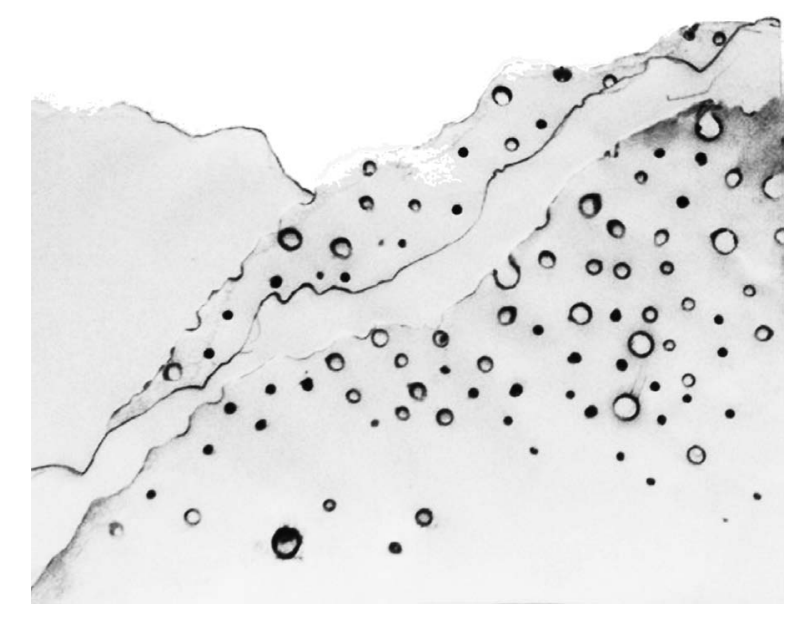

Por:

Juan José Cadavid Ochoa ${ }^{1}$

Profesor

Institución Universitaria Salazar y Herrera, Colombia

j.cadavid@iush.edu.co

Resumen: Este artículo plantea un acercamiento al concepto de formación, visto principalmente desde la perspectiva teórica de H. Georg Gadamer. Surge en el marco de la investigación "Construcción de un currículo transmedial alternativo para las artes” realizada por el grupo Código, inscrito a la Escuela de Artes de la Institución Universitaria Salazar y Herrera, y procura movilizar una reflexión que permita la construcción de estrategias de formación dinámicas e innovadoras que puedan ser aplicadas al saber artístico. El proceso investigativo que da origen al presente texto es de orden hermenéutico, en tanto realiza interpretaciones, comparaciones y apropiaciones de conceptos tratados teóricamente por distintos autores. Más que conclusiones taxativas, las revisiones y reflexiones realizadas pretenden movilizar preguntas en torno a la formación en artes y aportar, desde el campo de los estudios humanísticos o ciencias del espíritu, a la construcción de pensamiento crítico procesos de enseñanza y aprendizaje en y para las artes.

Palabras clave: Formación. Artes. Ciencia. Espíritu. Conocimiento. 

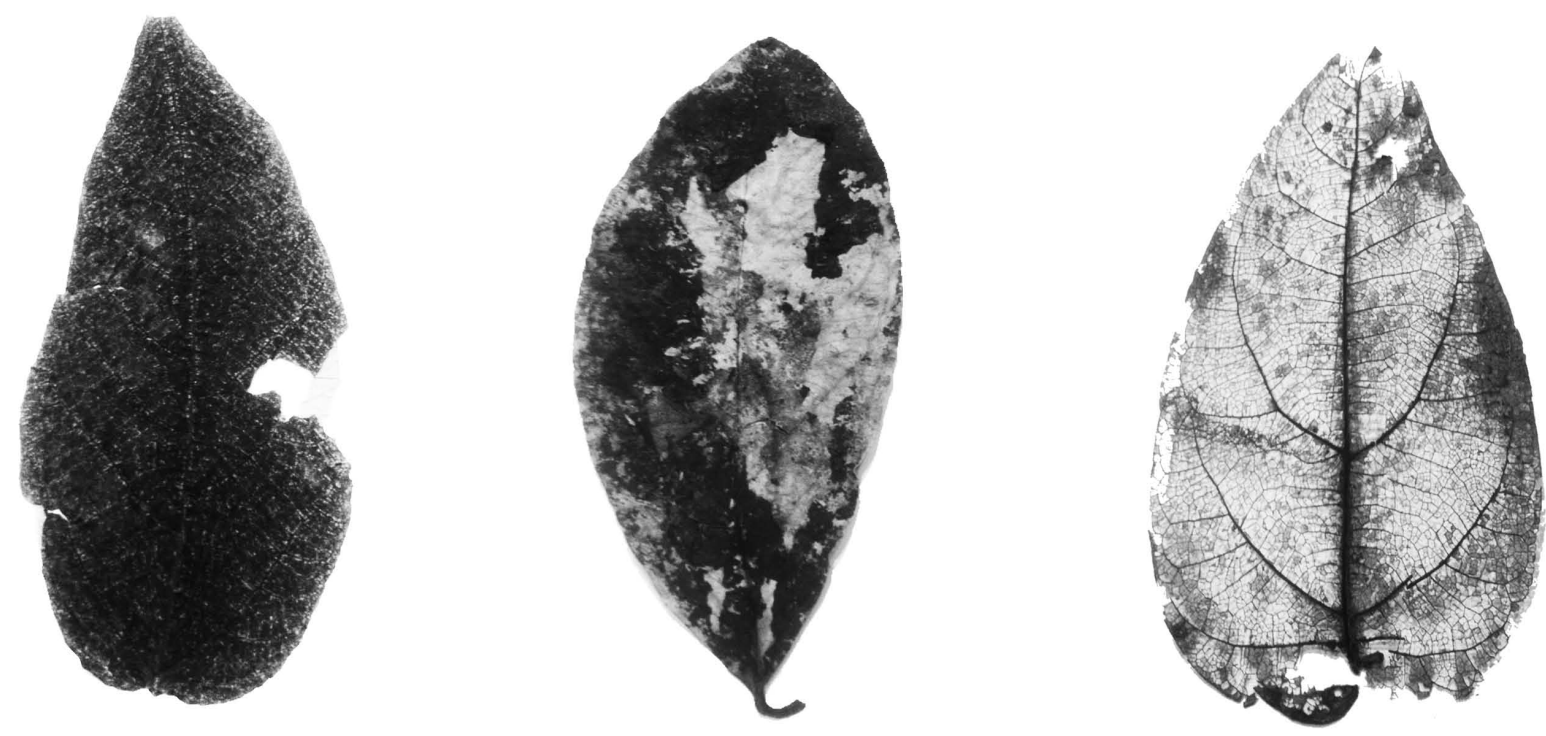

Abstract: This article presents an approach to the concept of training from the perspectives of H. Geoarg Gadamer. Arises in the research "Construction of a transmedial alternative curriculum for the arts" of Código group enrolled at the School of Arts of University Institution Salazar y Herrera, and seeks to mobilize a reflection about the construction of dynamics and innovative strategies to be applied to the artistic knowledge. The investigative process that gives rise to this text is hermeneutic, as made, interpretations, comparisons, and appropriation of concepts addressed theoretically by different authors. Rather than determinant conclusions, reviews and reflections made, intended to mobilize questions about arts education, and contribute from the field of the human sciences, for the construction of critical thinking processes of teaching and learning in and for the arts.

Key words: Training. Arts. Science. Humanities. Knowledge.

Resumo: Este artigo planteia uma aproximação ao conceito da formação, visto principalmente desde a perspetiva teórica de H. Georg Gadamer. O texto surge no contexto da pesquisa Construção de um currículo transmeia alternativo para as artes realizada pelo grupo Código, inscrito à Escuela de Artes da Institución Universitaria Salazar y Herrera, e procura suscitar uma reflexão que permita a formulação de estrategias de formação dinâmicas e inovadoras que possam ser aplicadas ao saber artístico. O processo de pesquisa que origina este texto é de natureza hermenêutica, pois realiza interpretações, comparações e apropriações de conceitos tratados teoricamente por diferentes autores. Mais que conclusões taxativas, as revisões e reflexões realizadas pretendem provocar perguntas ao redor da formação em artes, e aportar, desde o campo dos estudos humanísticos ou ciências do espírito, á construção de pensamento crítico, processos de ensino e aprendizagem em e para as artes.

Palavras-chave: Formação, artes, ciência, espírito e conhecimento. 


\section{Introducción}

La reflexión en torno a la significación de la tradición humanística para las ciencias del espíritu en relación con la pregunta por verdad del arte, propone un recorrido teórico que procura construir o dar sustento al concepto de formación. Este es el objetivo discursivo del presente texto. En él, primero se plantean algunas derivas teóricas de orden hermenéutico propuestas por H. Georg Gadamer desde las cuales es posible entender la relación del concepto formación con las ciencias del espíritu o lo que hoy se nombra como ciencias humanas; también desde este autor se propone más que una oposición a la idea de una metafísica del arte, una deconstrucción de la posibilidad de una única verdad del arte. Luego se revisará de manera sucinta la ruta que el concepto de formación ha recorrido en la historia del pensamiento occidental. Este rodeo epistemológico, construido a partir de postulados de diferentes autores, se dará de manera relacional entre tal concepto y la idea de arte para, desde esa relación, empezar a fundar las bases de un deber-ser contemporáneo de la formación artística. Más adelante se analiza la relación y las diferencias entre la formación y la memoria para, desde estos dos conceptos, entender cómo se hace posible la renovación del espíritu a partir de las distintas condiciones de vida y de la posibilidad del olvido. Más adelante, las consideraciones realizadas permiten la construcción de una explicación del concepto de formación en artes, como una idea que contiene, actualiza y renueva su propia historia, proyectándola en un contexto que se transforma constantemente en un proceso, siempre inacabado. Luego se plantean algunas oposiciones entre el concepto de formación y la idea de ilustración, tensiones que permiten definir finalmente en la contemporaneidad, y a manera de conclusión, un objetivo diferente en términos formativos, al de la acumulación de conocimientos.

\section{El giro espiritual de la ciencia}

El inicio de una ruta interpretativa y epistemológica para el concepto de formación en relación con las artes, puede situarse en el giro que Schiller le da a la propuesta de orden trascendental de Kant en torno al juicio del gusto y su prevención de validez general, transformando lo que puede constituir un presupuesto metódico en un presupuesto de contenido, este giro, de orden crítico y hermenéutico implica la deconstrucción del concepto de formación, o si se quiere la construcción intersubjetiva mismo. Schiller proclama al arte como una introducción a la libertad, como la posibilidad mediante la cual el hombre llega a ser humano; apoyando su declaración antropológicamente desde la base de teoría de los instintos, desde la cual la lúdica lograría la armonía entre el instinto de la forma y el instinto de la materia, por lo que, el objetivo de la educación estética tendrá que fundarse en el cultivo del instinto lúdico. Tal instinto lúdico, posee la cualidad de relacionar dos estados humanos: los estados de la razón y la sensibilidad, que si se cultivan de manera separada hacen que, según Schiller, el hombre sea un ser incompleto; "El impulso de juego [...] en la misma medida en que arrebate a las sensaciones y a las emociones su influencia dinámica, las hará armonizar con las ideas de la razón, y en la misma medida en que prive a las leyes de la razón de su coacción moral, las reconciliará con los intereses de los sentidos" (Schiller, 1990, p. 228). 
Este giro libera al arte de la condición de complementariedad en relación con la naturaleza y de la posibilidad de transformarla para el uso humano (que es la visión positivista del arte), y lo determina desde la oposición entre apariencia y realidad. El arte, y con él la condición sensible del ser humano, ya no se entiende de manera separada de su contraparte racional, de tal forma que el arte ya no se limita a complementar a la naturaleza, sino que también la enmascara, la transforma, la deforma o la oculta, transgrediendo los límites de la realidad. El marco abarcante que constituía la naturaleza se rompe y el arte "se convierte en un punto de vista propio y funda una pretensión de dominio propia y autónoma” (Gadamer, 2010, p. 122). La tragedia griega, y con ella las visiones apolíneas y dionisíacas del mundo, son, de esta forma, si no reformuladas, sí repensadas y visualizadas de nuevo como dualidades complementarias e indispensables del ser humano.

Una idea de formación artística puede hoy, en un giro aún más dramático, ser entendida como tragedia, al presentar una idea de proceso de construcción humana que se funda, ya no solo en el ordenamiento del conocimiento determinado por la visión apolínea del mundo, sino que incluye una perspectiva formativa que puede ser entendida como el surgimiento y la irrupción o, según Nietzsche, como el extático sonido de la fiesta dionisíaca, en el cual toda la desmesura de la naturaleza se revelaba a la vez en placer, dolor y conocimiento. Todo lo que hasta ese momento era considerado como límite, como determinación de la mesura, demostró ser aquí una apariencia artificial: la 'desmesura' se develó como verdad (Nietzsche, 1991, p. 9).

Los griegos erigieron dos divinidades como fuente de su arte: Apolo y Dionisio, que representan las dos antítesis estilísticas que siempre están en lucha constante. Cuando estas dos visiones se funden, se crea la tragedia, que es el estado en el que el ser humano está completo y alcanza la exuberancia de la existencia. Este es precisamente el doblez que se puede habitar en esta proyección artística formativa. De esta forma, es posible situar en el límite trágico al concepto de formación y observar cómo en esta grieta, en este intersticio, confluyen conceptos que parecieran oponerse, como público y privado, intimidad y banalidad, luz y oscuridad, correcto e incorrecto, doméstico y cosmopolita, afuera y adentro, virtual y real, individual y colectivo, lugar y espacio, razón y sensibilidad: oposiciones que definen y permiten la labor formativa del arte que se manifiesta en forma de encuentro. Pero tal reunión, o más bien, tal diálogo hoy continúa encontrando dificultades y críticas por parte de una muy fuerte tendencia cientificista de orden positivista que ha privilegiado históricamente la concepción racional del mundo de manera aislada.

La oposición a la concepción del arte a partir de la naturaleza, es la oposición al dogma metafísico que a partir de Kant había restringido el concepto del conocimiento a las posibilidades de la ciencia natural desde donde se le otorgó validez indiscutible al concepto de realidad. Esta categoría nominalista del ser estético es desmontada gracias a la crítica fenomenológica en contra de la psicología y la epistemología del siglo XIX desde la que se demuestra que el ser estético no depende de la experiencia de la realidad y que el arte no es una simple modificación de ésta. "El relegamiento de la 
determinación ontológica de lo estético al concepto de la apariencia estética tiene pues su fundamento teórico en el hecho de que el dominio del modelo cognoscitivo de la ciencia natural acaba desacreditando todas las posibilidades de conocer que queden fuera de esta nueva metodología” (Gadamer, 2010, p. 124).

El psicologismo pretendía ser método para solucionar algunas problemáticas que estaban presentes en la teoría del conocimiento, esto sin romper o transgredir los límites planteados por las posturas positivistas fundadas en la observación de hechos, una teoría fáctica que no aceptaba que los valores implicaran o permitieran la construcción de conocimiento. La idea del psicologismo se fundó en la idea cartesiana de entender a la conciencia y a la vida como una cosa, una realidad concreta, desde la que era posible construir un método experimental para el estudio de la vida anímica de animales y seres humanos, tal ciencia se llamó psicología. El objetivo de esta disciplina científica fue convertirse en una suerte de física del alma, pretensión fuertemente criticada por Husserl, quien afirmaba que no era posible una concepción del sujeto cognoscente por medio de una ciencia empírica que poseía una visión limitada de hombre como objeto entre objetos. La pretensión de la psicología de fundamentar el conocimiento, y con él toda posibilidad formativa en tanto evento psicológico producto de la razón científica, no solo fracasó, sino que terminó evidenciando, al intentar cerrar el círculo de la objetividad científica sobre sí misma, los propios límites de toda ciencia. Para Husserl el problema radicaba en que las posiciones de la ciencia fundamentada en la razón no tenían en cuenta que la mente humana no funciona en términos absolutos, ni para la concreción y objetivación de los hechos de la vida y la naturaleza, ni para lo efímero de las sensaciones, frente a lo cual el filósofo propone una ruta alternativa para conocer el mundo: la de acceder y construir el conocimiento a partir de estudiar los conceptos en un completo aislamiento interrogándolos desde las profundidades de su significado, entendiéndolos ya no como producto de un desarrollo genético, sino más bien como una construcción procesual de conexiones de significado, una ruta a la que llamaría la fenomenología.

Esta ruta es la que permite que hoy se continúe avanzando en la construcción de una significación y de un sentido para el concepto de formación estética, uno que pueda ser entendido a su vez, para la formación en artes de tal forma que tal constructo teórico se pueda ubicar dentro de lo que se ha llamado ciencias del espíritu. Por lo tanto, el concepto de formación estética no es elevado a ciencia de la misma manera que lo hacen las ciencias naturales, a partir de procedimientos de orden inductivo, puesto que su objetivo (el de formar) no es el de confirmar experiencias generales, leyes, sino comprender las particularidades de las experiencias humanas, buscando construir un conocimiento desde la comprensión del cómo, del proceso que produce dicho conocimiento. Por lo tanto, puede afirmarse que es el proceso de formación el que le da sentido al giro espiritual de esta ciencia, en tal sentido se usa el término alemán Bildung, que traducido como formación significa el resultado de un proceso que se da en relación con la tradición y el contexto. 
La idea de formación en Gadamer y de formación artística en esta reflexión, puede ser entendida en clave procesual, tanto desde lo general, puesto que este es un concepto en permanente devenir, como de manera particular y práctica, pues quienes se forman lo hacen en el tiempo. Del mismo modo, en oposición a la idea de un método que pretende contener leyes que rigen el conocimiento y las formas de acercarse a él, las ciencias del espíritu tratan "de comprender un fenómeno en su concreción histórica, es decir, se trata de comprender cómo algo ha llegado a ser lo que es y no de saber cómo es posible que sea así lo que así siempre ha sido” (Ríos, 1995, p. 17).

\section{Epistemología del concepto formación}

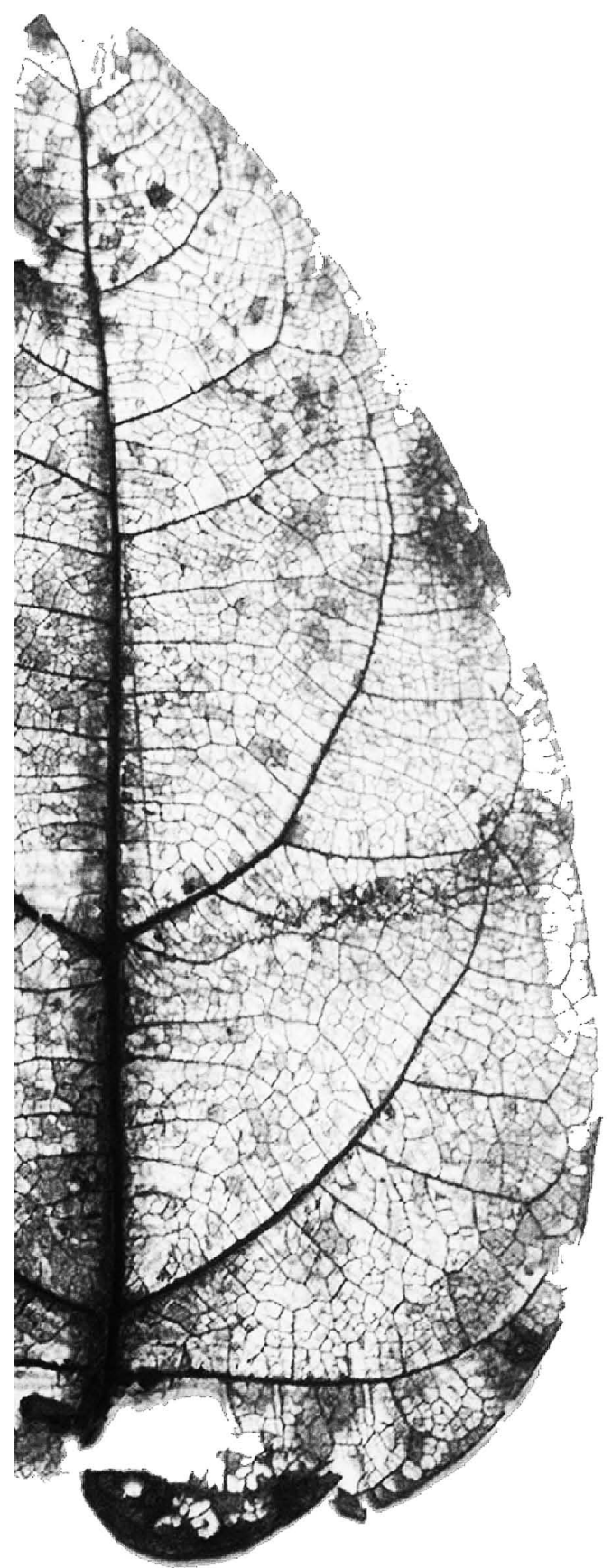

Para dar cuenta de manera general de la idea de formación, se recurre al concepto de Bildung, como un posible punto de partida. Este concepto se origina en la mística medieval y continúa presente en la del Barroco, por lo que puede decirse que viene determinado por características de orden religioso fundadas principalmente por el Mesías de Klostock. Su espiritualización es finalmente entendida por Herder como ascenso a la humanidad dejando de lado las referencias antiguas que lo relacionaban, como se ha dicho, con configuraciones producidas por la naturaleza para centrarse en una puramente humanística. Por esto, es posible vincular el concepto de formación a la cultura, pues este designa el modo específicamente humano de dar forma a las capacidades naturales del hombre, es este último sentido hederiano, el que acuñan Kant y Hegel. Kant no utiliza la palabra formación, sino que habla de la cultura, de la capacidad o de disposición natural de los conceptos que contienen las obligaciones para con uno mismo en procurar de no dejar perder los talentos propios. Hegel si utiliza la palabra formarse y formación para referirse a las obligaciones con sí mismo. Pero es W. Von Humboldt quien diferencia significativamente el concepto de cultura y el de formación, afirmando que: "cuando en nuestra lengua decimos formación nos referimos a algo más elevado y más interior, al modo de percibir que procede del conocimiento y del sentimiento de toda la vida espiritual y ética y se derrama armoniosamente sobre la sensibilidad y el carácter" (Gadamer, 2010, p. 30) relacionando el concepto de manera decidida con el desarrollo de capacidades y talentos. 
Puede decirse que ha existido una competencia entre el concepto Bildung y su equivalente latino, formatio que en inglés corresponde a form y formation, pero se ha impuesto el concepto de Bildung debido a que en éste está contenido imagen (Bild), mientras que la limitación del concepto de forma cede terreno frente a la duplicidad de Bild que contiene simultáneamente imagen imitada y modelo por imitar (Nachbild y Vorbild), por lo que el concepto de Bildung se acerca a la idea de ejemplo o referente a seguir, esta distinción determina que la actual formación responda, más al proceso que a los resultados, encontrándose siempre en desarrollo y progresión.

\section{La formación y el espíritu}

Hegel es quien con mayor fuerza ha desarrollado el concepto de formación. Su manera de entender el concepto se funda en la idea de reconciliación con uno mismo, en el reconocimiento de sí mismo en el ser otro, en ocuparse de lo extraño, de las asuntos pertenecientes al recuerdo, a la memoria y al pensamiento de manera teórica, para de esta forma enajenarse y llevar al hombre más allá de lo que sabe y experimenta de manera directa, reconociendo aquello que le es extraño en lo propio, haciéndolo familiar, es decir, entendiendo el constante retorno así como el fundamento esencial de la formación. Por lo tanto, su visión reúne de manera esencial al espíritu con la idea de formación.

La movilidad hacia el otro y lo otro, es decir, la posibilidad de comprender el mundo desde diferentes puntos de vista, permite entender la idea de formación como la capacidad de tomar distancia respecto a sí mismo, "y en esta misma medida un elevarse por encima de sí mismo hacia la generalidad. Verse a sí mismo y ver los propios objetivos privados con distancia quiere decir verlos como los ven los demás" (Gadamer, 2010, p. 47). Formarse entonces implica una apertura conceptual que supera las concepciones endogámicas del conocimiento y procura una visión general que incluye la reflexión sobre los discursos paralelos, contradictorios y ajenos, esto es, el reconocimiento de múltiples posibilidades de la verdad, por lo que la formación se funda no solo en la idea de un acuerdo sobre la verdad de la vida, sino más bien en una discusión permanente sobre sus posibilidades.

En la lección inaugural de su cátedra en la Universidad de Berlín, Hegel afirmaba que "La necesidad más seria es la de conocer. Es aquella por la cual el ser espiritual se distingue del ser puramente sensible y, por esto, es la necesidad más profunda del espíritu, y, por tanto, una necesidad universal. Esta necesidad se llama formación o el libre desarrollo de la razón humana y de los fines humanos” (Hegel, 1984, p. 13). En esta afirmación el filósofo disuelve nuevamente los márgenes trágicos de la antigua escisión poética.

El concepto de formación y con él la práctica formativa están en relación con la capacidad de recordar, pero esta relación no es en ningún caso una subordinación, sino más bien una característica en la que, la condición de la memoria está en una permanente tensión dinámica con la capacidad de olvidar, permitiéndole al 
espíritu humano una movilidad esencialmente libre, esto desde la posibilidad de enajenación autoconsciente que supera la capacidad de la memoria en tanto condición o disposición general de retener, olvidar y recordar, por lo que, la memoria tiene que ser formada; pues esta no es igual para todo. Se tiene memoria para unas cosas y otras son excluidas voluntariamente, por lo tanto el olvido constituye una manera de la memoria, según Nietzsche es una "condición de la vida del espíritu" (Gadamer, 2010, p. 45) y, por lo tanto, solo mediante el olvido "obtiene el espíritu la posibilidad de su total renovación, la capacidad de verlo todo con ojos nuevos, de manera que lo que es de antiguo familiar se funda con lo recién percibido en una unidad de muchos estratos" (Gadamer, 2010, p. 45).

La formación es, de acuerdo a las consideraciones revisadas, un proceso siempre en movimiento, una ruta trazada por el espíritu humano que no es en ningún caso indeleble o inmutable, sino que es cambiante. La formación no se puede referir entonces a la unicidad, ni a la uniformidad de los pensamientos y del conocimiento, es más bien todo lo contrario; la posibilidad de la libertad y en ella de las múltiples certezas. Es el camino por el cual se intenta alcanzar la conciencia de sí mismos y por consiguiente de entenderse y entender el mundo desde la perspectiva de los otros, de lo otro. El concepto de formación se refiere a la capacidad de crear no una, sino muchas formas, plétora de formas, es resultado de la posibilidad hermenéutica de la interpretación, la comprensión, la apropiación y la transformación del conocimiento, el resultado de la aceptación de que el método inductivo de las ciencias exactas no puede aplicarse en el caso de las ciencias cuyo objeto es el hombre. Esta maleabilidad del concepto de formación implica una oposición a la idea de ilustración, puesto que la acumulación de información puede resultar en un individuo o en una colectividad ilustrada, pero tal capacidad de almacenamiento y posiblemente de repetición o reproducción de la información no implica necesariamente la posibilidad de renovación y transformación de la información en conocimiento, que es en tanto proceso de cambio y construcción de formas, lo que implica la formación.

\section{Dificultades con la Ilustración}

El concepto de ilustración es abordado en esta parte de la reflexión, pues históricamente se ha relacionado si no directamente con la educación, sí como consecuencia de ésta. El concepto es revisado solo desde esta perspectiva, pues su rendimiento e implicaciones teóricas son extensas y no se pretende abarcar tal amplitud. Para interrogarlo se acude al filósofo José Luis Villacañas Berlanga y a su libro: Dificultades con la ilustración, variaciones sobre temas kantianos. En éste, el autor no se refiere con el término "Dificultades" a que el programa de la Ilustración haya quedado insatisfecho, por lo tanto, no se trata de un fracaso del programa. Se trata de las dificultades para encontrar un sentido filosófico apropiado a tal idea (Villacañas, 2013, p. 9). Tal complejidad puede ser puesta en relación con el concepto (posterior) de formación, para encontrar las condiciones adecuadas que realicen o nieguen dicha condición ilustrada, y de esa forma identificar posibles premisas educativas. 
La ilustración como concepto presenta una condición inmóvil en la que el conocimiento reposa, una persona ilustrada ya posee la información necesaria sobre la vida y su espíritu ha encontrado sosiego. Pero además de tal quietud, el proceso por medio del cual se llega a la ilustración parece fundar su proceder en el disfrute de la conducción, de tal forma que los tutores y doctos son quienes determinan el camino hacia la iluminación. La idea de formación por el contrario implica cierta incomodidad pues para realizar un proyecto de emancipación humana es necesario comprender que el proceso implica emprender una batalla en la que el dinamismo y la oposición de las ideas producen conocimiento, un conocimiento que no es definitivo y no puede verterse como saber absoluto sobre alguien. Puede decirse que mientras la ilustración procura consensos, la formación produce disenso, esto es; la tensión entre la información enciclopédica, es decir contenida y el conocimiento en constante construcción, fruto del debate y la revisión constante de los presupuestos.

Kant aclara la idea de incomodidad como sentimiento generador de dinámicas capaces de movilizar y crear conocimiento. Compara la idea de ilustración en tanto condición estática y cómoda del conocer humano con las dimensiones subjetivas de los encadenados platónicos, a las que nombró como pereza. Esto desde la perspectiva platónica de la fuerza de la costumbre, en la que se ilustra tal comodidad a partir de los efectos inerciales de los hábitos de los presos, la adaptación del cuello y los brazos a los grilletes y de los ojos a las circunstancias apropiadas del claroscuro y las sombras. La pereza es, por lo tanto, la base subjetiva de la comodidad, y tal condición puede encontrar sus raíces más allá de las explicaciones antropológicas, pues existen pulsiones de automatismo que producen una inclinación a hacer lo ya hecho, costumbres de repetición que no son en ningún caso el objeto de la formación del espíritu que implica, por el contrario, y como se ha dicho: la diferencia, la contrariedad, la dislocación, la mirada desde otros puntos de vista y por lo tanto la continua movilidad y construcción de conocimiento. La ilustración o la condición estática del conocimiento según esta reflexión, puede producir situaciones en las que se considera completamente verdadero a algo, un estado de seguridad y confort muy cómodo y placentero.

El arte, por su parte, tiene un carácter renovador, revolucionario, subversivo y transformador. Su vocación es la del dinamismo, la del movimiento constante y por lo tanto, ni el método, en tanto manera general y normativa de creación, ni la verdad, como única posibilidad o ley absoluta, configuran una ruta viable para las prácticas artísticas y, por lo tanto, la formación en este campo del conocimiento sensible, centrado en el ser humano, tampoco puede responder a dinámicas exactas, lineales y unidireccionales.

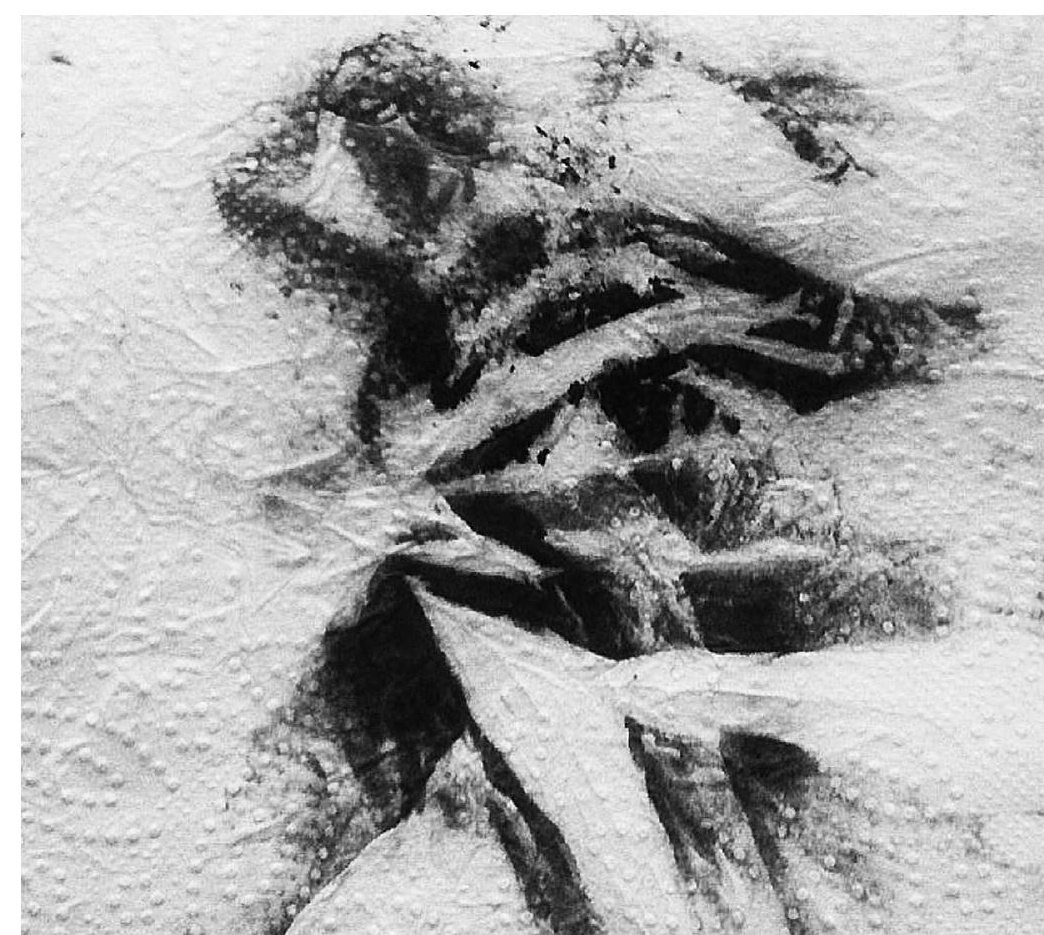


Las dificultades propuestas por Villacañas, buscan disponer en relación con el proyecto ilustrado, "de una adecuada retórica capaz de producir efectos materiales en algo que no puede ser sino una teoría de la educación [...] Así que quizá la retórica de la Ilustración ha fallado por un fracaso en la teoría, pero en todo aún necesitaría de una retórica adecuada, pues ya se dejaría ver cómo una adecuada teoría del concepto no puede abrirse camino sin una teoría de la metáfora" (Villacañas, 2013, p. 24). Por lo tanto, el pensamiento estético y la práctica artística, constituyen un hábitat ideal para la puesta en acción de una teoría de la metáfora, que movilice la idea de ilustración, superándola en una praxis que constituye el fundamento de la educación artística como parte de la condición de aprensión y resignificación simbólica del arte mismo y del mundo.

La formación en artes no pretende estados ilustrados de la conciencia, sino que procura movilizar paradigmas, generando incomodidad, inconformidad y tensión sobre todo aquéllo que parece establecerse como verdadero. Esta condición le permite al arte reinventar al mundo a partir de la construcción permanente de su conocimiento.

\section{Conclusión: Trayectos formativos o las diferentes rutas para la construcción del conocimiento}

Intentar explicar el concepto de formación puede generar, como la idea que lo define, interminables rodeos y movimientos discursivos, pues es esa dinámica la que anima su propia razón sensible de ser. Puede decirse, con y desde Gadamer, que éste es un concepto esencialmente hermenéutico pues su acción no es del orden de la definición, de la comodidad y de la ilustración, sino que, por el contrario, su aplicación implica una interpretación y una apropiación particular, diferente y cambiante del mundo. La formación a través de la observación desde diferentes puntos de vista y desde el continuo estado de incomodidad, permite movimientos y procesos de construcción de conocimiento que nunca están terminados y que, por lo tanto, no tienen como objetivo construir e instalar verdades absolutas, sino que procuran certezas, verdades cambiantes como los contextos, la historia, el mundo y el hombre mismo. 
La condición dinámica de la formación en artes, implica una coherencia contextual, esto implica que la base del ideal de hombre y las sociedades que se quieren formar, se relaciona directamente con la cultura en la que se da tal proceso. El ideal formativo debe sincronizarse con el devenir histórico y, por lo tanto, debe ser recreado para dar cuenta de los cambios que se dan en el tiempo, construyendo formas nuevas de conexión con el mundo, maneras que permiten transformarlo y generar diversas formas culturales.

Actualmente puede decirse que los conocimientos están interconectados, la diversidad cultural se hace fuerte y al mismo tiempo se generan formas híbridas; manifestaciones culturales emergentes que mutan a gran velocidad. En un contexto como este, los procesos formativos no pueden ser ni lineales, ni estáticos, sino que deben construirse de acuerdo a los proyectos ideales de las personas que están en formación, ideales que no son determinados por disciplinas estrechas, sino más bien, por intereses en conocimientos amplios, en saberes conectados y expandidos. Es así que los proyectos formativos contemporáneos permiten, que sobre una cartografía multicultural; se tracen trayectos móviles, desde los que se puede construir y validar, múltiples conocimientos.

Hoy la sincronía de la formación con el devenir histórico implica no solo la diversidad, sino también la capacidad de cambiar de dirección para conectar distintos saberes y producir, ya no un conocimiento compartimentado, segmentado y aislado, sino muchas posibilidades intersubjetivas de él. Esta condición no implica una especie de anarquía formativa, pero sí exige una transformación en el papel de aquél encargado de formar. Como se ha dicho, ya no se entiende el rol del formador, como el de aquél que dicta un conocimiento que debe ser repetido, sino que, como dice Gadamer; "las enseñanzas de un maestro pueden ofrecer cierta ayuda" (Gadamer, 2010, p. 307). Esta ayuda se puede entender como una provocación reflexiva que tiene como finalidad evitar errores. Esta función del maestro no es menor, ni implica cierta laxitud. Para ilustrar la responsabilidad del formador, Gadamer acude a Platón, y con él a una metáfora gastronómica:

Este llama a las ciencias que constan de logos o discursos, alimento del alma, como los manjares y las bebidas son alimento del cuerpo. 'Por eso deberíamos ser igualmente desconfiados en su adquisición, para que no nos endosen una mala mercancía. Hay mucho mayor peligro en la adquisición del saber que en la compra de alimento. Porque los manjares y las bebidas que uno compra al tendero puede llevarlas a casa en recipientes especiales y, antes de consumirlas, puede depositarlas en casa y aconsejarse de un experto para saber lo que puede comer o beber y lo que no, y en qué cantidad y cuándo. Por eso la compra no supone un gran peligro. Pero el saber no se puede llevar a casa en recipientes especiales, sino que es inevitable asimilarlo directamente en el alma una vez pagado el precio, y dejamos adoctrinar por él [...] para bien o para mal (Gadamer, 2010, p. 58). 
Es responsabilidad del maestro mostrar, acompañar, evidenciar y comprobar que los distintos trayectos de construcción de conocimiento por los que transitan aquellos en proceso de formación, les permitirán además alcanzar sus ideales y un desarrollo económico-técnico, además comprender que son las diferencias insalvables: culturales, políticas, sociales, históricas y naturales, las que hacen que los hombres puedan entenderse y unirse como seres humanos. Es así como los maestros, tienen sobre todo la exigencia apremiante de ayudar a construir una conciencia sobre la diferencia y, por lo tanto, una educación en y para la tolerancia.

\section{Notas}

${ }^{1}$ Especialista en Intervención Creativa, Colegiatura Colombiana, Medellín. Magister en Estudios Humanísticos. Candidato a doctor en Humanidades, EAFIT, Medellín.

\section{Referencias}

Gadamer, H. (2010). Verdad y método I. Salamanca. Ediciones Sígueme.

Gadamer, H. (2010). Verdad y método II. Salamanca. Ediciones Sígueme.

Hegel, G. (1984a). Lecciones sobre filosofía de la religión. Madrid: Alianza Editorial.

Nietzsche, F. (1991). El origen de la tragedia. Barcelona: Espasa Libros.

Ríos, C. (1995). Un acercamiento al concepto de formación en Gadamer. En: Revista Educación y Pedagogía. $\mathrm{N}^{\circ} 14-15$. Medellín: Facultad de Educación. Universidad de Antioquia.http: // tesis.udea. edu.co/jspui/bitstream/10495/3181/1/RiosClara_1995_ acercamientoconceptoformaciongadamer.pdf

Schiller, F. (1990). Cartas sobre la educación estética del hombre. Barcelona: Anthropos.

Villacañas, J. (2013). Dificultades con la Ilustración.Variaciones sobre temas kantianos. Madrid: Verbum. 